\title{
Aplicação do sistema de análise de perigos e pontos críticos de controle em propriedade leiteira tipo $A$
}

\author{
Application of hazard analysis and critical control points system in a grade A dairy farm
}

\author{
Andrezza Alves Spexoto ${ }^{1}$ Carlos Augusto Fernandes Oliveira ${ }^{2}$ Alexandre de Azevedo Olival ${ }^{1}$
}

\section{RESUMO}

O sistema de análise de perigos e pontos críticos de controle (APPCC) constitui um importante método preventivo empregado na linha de produção de alimentos, tendo sido aplicado com sucesso em propriedades leiteiras para o controle de agentes patogênicos e de resíduos de medicamentos. Este trabalho objetivou avaliar a eficiência e os principais problemas relacionados à aplicação do sistema APPCC em uma propriedade produtora de leite tipo A, com vistas ao controle dos níveis de células somáticas (CS) e da carga microbiana no leite do rebanho, bem como do resultado do exame California Mastitis Test (CMT) obtido individualmente nos animais. Após a aplicação do sistema, não houve alterações na contagem média de CS no leite e no percentual de casos de mastite, porém, observou-se uma diminuição $(P<0,05)$ no número de quartos afetados e no escore de mastite, estimados pelo teste CMT. As contagens de mesófilos e psicrotróficos não diferiram $(P>0,05)$ antes $e$ após a aplicação do sistema. Entretanto, os valores de coliformes fecais no leite foram reduzidos $(P<0,05)$, demonstrando que a aplicação do sistema foi eficiente para melhorar as condições sanitárias do leite. Ressalta-se a importância do comprometimento dos funcionários e do proprietário como fator essencial para o sucesso do sistema APPCC em granjas leiteiras.

Palavras-chave: APPCC, células somáticas, bacteriologia, leite, qualidade.

\section{ABSTRACT}

The hazard analysis and critical control points (HACCP) system is an important preventive method used in food production process, having been applied successfully in dairy farms for the control of pathogenic organisms and veterinary drug residues. The aim of the present work was to evaluate the efficiency and the main problems related to the application of HACCP system in a grade A dairy farm, to control the levels of bulked milk somatic cell counts (SCC) and microbial load, as well as the individual CMT - California Mastitis Test. The average SCC in bulked milk and the percentage of mastitis (as estimated by the CMT) were not affected after the system application. However, a reduction $(P<0.05)$ in the number of affected quarters and mastitis score was observed. Mesophile and psychrotrophic counts in milk were not different $(P>0.05)$ before and after the application of HACCP. However, fecal coliforms values decreased $(P<0.05)$ in milk, hence indicating the system efficiency for the improvement of sanitary conditions of milk. The importance of both farm owner and staff commitment as an essential factor for the success of HACCP system in dairy farms is stressed.

Key words: HACCP, somatic cells, bacteriology, milk, quality.

\section{INTRODUÇÃO}

A Análise de Perigos e Pontos Críticos de Controle (APPCC) é definida como um conjunto sistemático de atividades utilizadas para o controle da produção de alimentos, garantindo a segurança e a qualidade dos alimentos (SOARES et al., 2002).

Existem sete princípios básicos que devem ser seguidos para a implementação do APPCC, em ordem: identificar os perigos potenciais; determinar os pontos críticos de controle (PCCs); estabelecer os limites críticos; estabelecer uma rotina de

${ }^{1}$ Faculdade de Medicina Veterinária e Zootecnia (FMVZ), Universidade de São Paulo (USP), São Paulo, SP, Brasil.

${ }^{2}$ Faculdade de Zootecnia e Engenharia de Alimentos, USP. Av. Duque de Caxias Norte 225, 13635-900, Pirassununga, SP, Brasil. E-mail: carlosaf@usp.br, Autor para correspondência. 
monitoramento; estabelecer ações corretivas; estabelecer um efetivo sistema de anotações; e, estabelecer um sistema de verificação para dar continuidade ao APPCC (CEZARI \& NASCIMENTO, 1995).

O sistema APPCC tem sido utilizado, rotineiramente, nos processos industriais de elaboração de alimentos (MARTIN \& CICHOSKI, 2000). Entretanto, vários autores têm reportado que o sistema constitui ferramenta importante, também, para o controle de matérias primas, particularmente do leite em propriedades rurais (CULLOR, 1997; SISCHO, 1996).

A contagem de células somáticas (CCS) compreende o total de células presentes no leite, as quais podem ser do tipo epitelial ou de defesa (RIBAS, 1999). Assim, a CCS tem sido considerada como um dos mais importantes indicadores do estado sanitário da glândula mamária em rebanhos leiteiros, sendo um fator diretamente relacionado com a ocorrência de mastite no rebanho. Conforme destacam MILLER et al. (1993), a mastite é um dos mais importantes problemas sanitários que afetam a produção de leite, sendo considerada como a mais onerosa doença que acomete os bovinos leiteiros, ocasionando perdas de volume e qualidade do leite.

De acordo com FONSECA \& SANTOS (2000), a carga microbiológica do leite pode ser um indicativo da qualidade sanitária do rebanho e das condições higiênicas na produção do leite. Os principais microrganismos relacionados com a alteração da qualidade do leite compreendem os mesófilos e os psicrotróficos, tendo em vista que as bactérias patogênicas, de modo geral, estão incluídas entre os primeiros, enquanto o segundo grupo engloba vários tipos de microrganismos capazes de produzir alterações físicas, químicas e sensoriais no leite (SPREER, 1991).

O objetivo do presente trabalho foi avaliar a eficiência e os principais problemas relacionados à aplicação do sistema APPCC em uma propriedade produtora de leite tipo A, com vistas ao controle dos níveis de células somáticas (CS) e da carga microbiana no leite do rebanho, bem como do resultado do exame CMT - California Mastitis Test obtido individualmente nos animais.

\section{MATERIAL E MÉTODOS}

A propriedade utilizada foi uma granja produtora de leite $\mathrm{A}$, localizada no município de Descalvado/SP, sendo constituída por 128 animais da raça Holandesa em lactação, com produção média de $28 \mathrm{~kg}$ de leite vaca $^{-1} \mathrm{dia}^{-1}$, totalizando $3.584 \mathrm{~kg}$ de leite dia $^{-1}$, obtidos através de três ordenhas diárias. A granja possuía ordenhadeira mecânica (tipo espinha de peixe) para a ordenha simultânea de 16 vacas, sendo o leite canalizado e armazenado em tanque de expansão.

Previamente à aplicação do sistema APPCC, foram realizadas as seguintes atividades necessárias à implantação do sistema, de acordo com CEZARI \& NASCIMENTO (1995) e SERVIÇO NACIONAL DA INDÚSTRIA (2000): obtenção do comprometimento e formação da equipe de trabalho, descrição da propriedade e do pessoal envolvido na ordenha, aplicação e treinamento em Boas Práticas de Produção e Manipulação (BPPM) e descrição do fluxograma das operações de ordenha. Para a primeira atividade, foram realizadas duas reuniões iniciais com o proprietário e os funcionários envolvidos com a ordenha, com a finalidade de informar os resultados esperados e os benefícios gerados no trabalho. A descrição da propriedade e do pessoal envolvido na ordenha foi realizada através de entrevistas individuais estruturadas (BOGDAN \& BIKLEN, 1994), com a finalidade de detalhar o manejo geral da propriedade, as condições da infra-estrutura existente e o grau de conhecimento da equipe sobre o tema "qualidade do leite”. Os dados apurados neste diagnóstico foram utilizados para a elaboração de cartilhas de apoio didático, de acordo com os critérios recomendados por RONCA \& ESCOBAR (1988), para uso em reuniões de treinamento sobre BPPM. A descrição do fluxograma das operações de ordenha possibilitou o levantamento dos perigos envolvidos em todo o processo de ordenha, conforme previsto na metodologia para aplicação do sistema APPCC (SILVA \& GOMES, 2001). Para isso, realizou-se a observação simples dos trabalhos de ordenha, registrando-se os detalhes da seqüência de manejo dos animais e das demais operações em um formulário específico (BOGDAN \& BIKLEN, 1994).

Após a realização das etapas anteriores, foram constituídos grupos de trabalho formados pelos funcionários da propriedade (que receberam diferentes funções) e pelos coordenadores da pesquisa, para aplicação integral dos princípios do sistema APPCC, a seguir relacionados: Identificação de todos os perigos potenciais relacionados com o aparecimento da mastite clínica e sub-clínica, além da contaminação bacteriana do leite; definição das medidas preventivas para os perigos acima, para fins de identificação dos PCCs (árvore decisória); estabelecimento dos limites críticos, de acordo com referências disponíveis na literatura especializada, conceitos e bom senso (CEZARI \& NASCIMENTO, 1995); monitoramento dos PCCs, com vistas à verificação do cumprimento dos limites 
críticos; estabelecimento de ações corretivas, caso algum limite crítico fosse ultrapassado, através de intervenções no fluxograma de produção, como alterações no manejo dos animais e nas operações de ordenha, entre outros; documentação de todas as atividades desenvolvidas para a implantação do sistema, bem como registro dos dados referentes à identificação e monitoramento dos PCCs, limites críticos adotados e ações corretivas / preventivas; verificação e avaliação periódica do funcionamento de todo o sistema, através de medidas que confirmassem o funcionamento adequado do sistema e por meio de testes (análises de CCS e da carga microbiana no leite do rebanho, e exame CMT dos animais, individualmente) realizados no início da implementação completa do sistema e ao final do projeto.

Os registros de todas as reuniões educativas (treinamento em Boas Práticas e APPCC, entre outras) foram tratados como dados qualitativos, sendo transcritos e submetidos à análise de codificação, segundo a proposta de PEREIRA (2001).

A eficiência do sistema APPCC foi avaliada através de análises para a determinação da carga bacteriana e celular no leite obtido na propriedade. Para a análise microbiológica, realizou-se a colheita asséptica de 1 amostra (500mL) de leite, retirada diretamente do tanque de armazenagem (monitorado e mantido a $4^{\circ} \mathrm{C}$ ), durante 4 semanas, sendo uma colheita por semana, de acordo com as normas de VEISSEYRE (1972). As amostras foram submetidas, imediatamente, ao exame microbiológico para a contagem de microrganismos mesófilos e psicrotróficos, e determinação do número mais provável (NMP) de coliformes a 30 e $45^{\circ} \mathrm{C}$ (AMERICAN PUBLIC HEALTH ASSOCIATION, 1992). Os resultados foram expressos em unidades formadoras de colônias (UFC) $\mathrm{mL}^{-1}$ ou $\mathrm{NMP} / \mathrm{mL}$.

Para a avaliação da carga celular, foram efetuadas análises de CCS no leite de mistura da propriedade, através da colheita de uma amostra (100 mL) semana ${ }^{-1}$ do tanque de armazenagem, nas mesmas quatro semanas. As amostras foram conservadas em frascos contendo $8 \mathrm{mg}$ de bronopol (2-bromo-2-nitropropano-1,3-diol) e encaminhadas para análise laboratorial através de contador eletrônico de células somáticas (Bentley®), sendo o resultado expresso em número de células/mL.

Os procedimentos de amostragem (uma amostra semana ${ }^{-1}$, durante quatro semanas) e análise do leite foram repetidos no início do experimento (antes do diagnóstico da propriedade, realizado em setembro/ 2002), após o treinamento em BPPM (concluído em fevereiro/2003) e após a implantação completa do sistema APPCC (em junho/2003), totalizando três períodos de coleta.

Adicionalmente, foram realizadas análises de CMT (AMERICAN PUBLIC HEALTH ASSOCIATION, 1992) no leite individual das vacas, para estimativa da ocorrência de casos de mastite no rebanho durante a execução do experimento. Do início do experimento (setembro/2002) ao término da implantação do sistema APPCC (junho/2003), foram realizadas 15 amostragens para o teste CMT, com intervalo de aproximadamente 15 dias entre cada uma. Apesar de não terem sido realizados testes microbiológicos no leite dos animais, para determinar os microrganismos patogênicos causadores de mastite, consideraram-se os escores do exame de CMT como indicativo da presença de mastite nos animais. A partir da leitura e interpretação do teste, foram calculados os seguintes índices: Número de Quartos Afetados por mastite (NQA), representado pelo número médio de quartos mamários por animal, cujo leite apresentou positividade (pelo menos uma cruz) ao exame de CMT; Escore de Mastite (EM), com valores variando 0 a 4 , correspondentes às leituras obtidas no exame CMT (negativo, traço, uma cruz, duas cruzes ou três cruzes, respectivamente); Porcentagem de Vacas com Mastite (\%VM), considerando-se todos os animais cujo leite apresentou positividade ao exame de CMT; Porcentagem de Vacas com Mastite Crônica (\%VMC), considerando-se os animais cujo leite apresentou positividade ao exame de CMT em pelo menos um quarto, durante dois meses consecutivos; e, Porcentagem de Novos Casos de Mastite (\%NCM), considerando-se os animais cujo leite apresentou positividade ao exame de CMT realizado no mês, mas não no mesmo teste realizado no mês anterior.

Os resultados obtidos nas análises microbiológicas e de CCS foram convertidos em Log, após o que foram submetidos à análise de variância, utilizando-se para a comparação entre as médias, quando aplicável, o teste de Tukey. As diferenças entre os valores obtidos para NQA e EM nas diferentes amostragens foram avaliadas através do Teste de Friedman. Para os dados referentes à \%VM, \%VMC e \%NCM, utilizou-se o Teste Q de Cochran. Todas as análises estatísticas foram realizadas no programa SPSS, em nível de 5\% de significância (ARMITAGE \& BERRY, 1987).

\section{RESULTADOS E DISCUSSÃO}

Foram observadas 20 etapas do fluxograma de obtenção de leite relacionadas com a ocorrência de 
perigos para a mastite e contaminação bacteriana, totalizando o levantamento de 43 perigos. Após o detalhamento destes 43 perigos, de acordo com a sua colocação na árvore decisória citada por SILVA \& GOMES (2001), foram definidos e categorizados 35 pontos críticos de controle.

Durante o experimento, os PCCs sofreram evolução, demonstrando a facilidade ou dificuldade do controle, e a diminuição ou erradicação de alguns perigos. Perigos relacionados com a efetividade do pre-dipping, limpeza dos equipamentos na existência de animais com mastite, fonte e qualidade microbiológica da água e tratamento da mastite clínica, permaneceram totalmente controlados desde o início da implantação do sistema APPCC. Perigos relacionados ao estresse animal, superlotação e pisoteio na sala de espera, procedimento de secagem do teto dos animais, limpeza de teteiras e equipamentos de ordenha, contaminação da teteira durante o procedimento de ordenha, funcionamento dos equipamentos de ordenha, tempo de ordenha, tempo de colocação de teteiras e formação de leite residual, transmissão de mastite clínica por animais não curados, aplicação dos medicamentos contra mastite, avaliação do pos-dipping e condições de pasto, apresentaram, em alguns momentos da pesquisa resultados insatisfatórios quanto aos limites críticos estabelecidos. Alguns perigos não puderam ser controlados por motivos variados, tais como controle de vacas secas (devido à falta de dados do retorno dos animais, por motivo de venda) e funcionamento e limpeza do tanque de resfriamento do leite (devido ao grau de dificuldade na realização de ações preventivas).

A tabela 1 apresenta o número de perigos não controlados e os resultados obtidos nas contagens de CS e análises microbiológicas do leite de mistura nas três ocasiões de amostragem (início do experimento, após treinamento em BPPM e após a implantação do APPCC). O número de perigos não controlados variou de 10 após o treinamento em BPPM (segunda amostragem), para 5, após a implantação do sistema APPCC (terceira amostragem). Os perigos não controlados na segunda amostragem foram: transmissão de mastite clínica na sala de espera, limpeza final de tetos, limpeza do equipamento de ordenha, funcionamento do equipamento de ordenha, tempo de colocação de teteiras, tempo de ordenha, aplicação pos-dipping, condição dos pastos, procedimento de secagem e limpeza e funcionamento do tanque. Os perigos não controlados na terceira amostragem foram: transmissão de mastite clínica na sala de espera, tempo de ordenha, aplicação pos- dipping, procedimento de secagem e limpeza do tanque.

Houve um ligeiro aumento da CCS (de 5,39 para 5,80Log céls. $\mathrm{mL}^{-1}$ ) após o treinamento em BPPM, porém, retornando a um valor $\left(5,48 \mathrm{Log}\right.$ céls. $\left.\mathrm{mL}^{-1}\right)$ próximo do inicial após a implantação do sistema APPCC. Entretanto, deve-se considerar que os valores médios obtidos em todas as amostragens estiveram dentro do limite (máximo de 600.000céls. ml-1) estabelecido pela legislação (BRASIL, 2002). Portanto, não foram observados efeitos da implantação do sistema APPCC sobre a CCS do leite de mistura.

As contagens de microrganismos mesófilos (tabela 1) não diferiram entre as amostragens $(\mathrm{P}>0,05)$, mas também sofreram um acréscimo entre a primeira e a segunda amostragem, observando-se uma redução de mais de um ciclo logarítmico após a implantação do sistema appcc. No entanto, as contagens de mesófilos estiveram acima do limite preconizado (máximo de 10.000ufc $\mathrm{ml}^{-1}$ ) pela legislação para o leite tipo a (BRASIL, 2002). FONSECA \& SANTOS (2000) destacaram que contagens acima de 5,90log ufc ml-1, como a observada na segunda amostragem, indicam baixo padrão de higiene, podendo causar prejuízos na qualidade do leite. Quanto ao número de psicrotróficos, embora tenha havido um aumento $(\mathrm{P}<0,05)$ somente após o treinamento em bppm (segunda amostragem), os valores observados em todas as amostragens apresentaram-se de acordo com a legislação, ou seja, abaixo de $10 \%$ do total de microrganismos no leite (BRASIL, 1976).

Não foram observadas diferenças $(\mathrm{P}>0,05)$ entre os valores obtidos nas amostragens para coliformes a $30^{\circ} \mathrm{C}$, sendo que os níveis de coliformes a $45^{\circ} \mathrm{C}$ diminuíram $(\mathrm{P}<0,05)$ após a implantação do appcc. A legislação brasileira não inclui limites para coliformes no leite cru refrigerado tipo a. PHILPOT \& NICKERSON (2002) classificam como "excelente" e "bom" o leite contendo coliformes totais $\left(30^{\circ} \mathrm{C}\right)$ e fecais $\left(45^{\circ} \mathrm{C}\right)$ em níveis abaixo de $10 \mathrm{nmp} \mathrm{ml}^{-1} \mathrm{e}$ entre 10 a $100 \mathrm{nmp} \mathrm{ml}^{-1}$, respectivamente. Aplicando-se esta classificação aos resultados obtidos na amostragem realizada após a implantação do sistema appcc (Tabela 1), o leite de mistura da propriedade apresentou valores de coliformes totais e fecais considerados como "bom" e “excelente”, respectivamente.

A figura 1 apresenta os resultados do exame cmt em 15 amostragens realizadas entre o início e o término da implantação do sistema appcc. Os valores de nqa variaram significativamente $(\mathrm{P}<0,05)$ com a implantação do sistema appcc, diminuindo de aproximadamente 2 para 1 quarto afetado por vaca. Similarmente, os valores de em também diminuíram 
Tabela 1 - Perigos não controlados e resultados das contagens de células somáticas (CCS) e análises microbiológicas no leite de mistura, de acordo com a ocasião da amostragem.

\begin{tabular}{|c|c|c|c|c|c|c|}
\hline \multirow{2}{*}{ Amostragem } & \multirow{2}{*}{$\begin{array}{c}\text { Perigos não } \\
\text { controlados (N) }\end{array}$} & \multirow{2}{*}{$\begin{array}{c}\mathrm{CCS} \\
\left(\log \mathrm{N} \mathrm{mL}^{-1}\right)^{1}\end{array}$} & \multirow{2}{*}{ 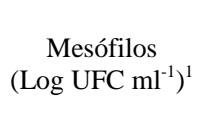 } & \multirow{2}{*}{$\begin{array}{l}\text { Psicrotróficos } \\
\left(\text { Log UFC ml }{ }^{-1}\right)^{1}\end{array}$} & \multicolumn{2}{|c|}{$\begin{array}{c}\text { Coliformes } \\
\left(\text { Log NMP ml }{ }^{-1}\right)^{1}\end{array}$} \\
\hline & & & & & $30^{\circ} \mathrm{C}$ & $45^{\circ} \mathrm{C}$ \\
\hline Início do experimento & - & 5,39 & 5,76 & $2,40^{\mathrm{a}}$ & 1,95 & $1,23^{\mathrm{a}}$ \\
\hline $\begin{array}{l}\text { Após treinamento em } \\
\text { BРPМ* }^{*}\end{array}$ & 10 & 5,80 & 6,22 & $4,80^{b}$ & $>2,04$ & $1,45^{\mathrm{a}}$ \\
\hline $\begin{array}{l}\text { Após implantação do } \\
\text { APPCC** }\end{array}$ & 5 & 5,48 & 4,98 & $2,98^{a}$ & 2,04 & $0,11^{b}$ \\
\hline
\end{tabular}

${ }^{1}$ Resultados expressam a média de 4 amostras colhidas com intervalo de 1 semana.

N - Número. UFC - Unidades formadoras de colônias.

* BPPM - Boas Práticas de Produção e Manipulação.

** APPCC - Análise de Perigos e Pontos Críticos de Controle.

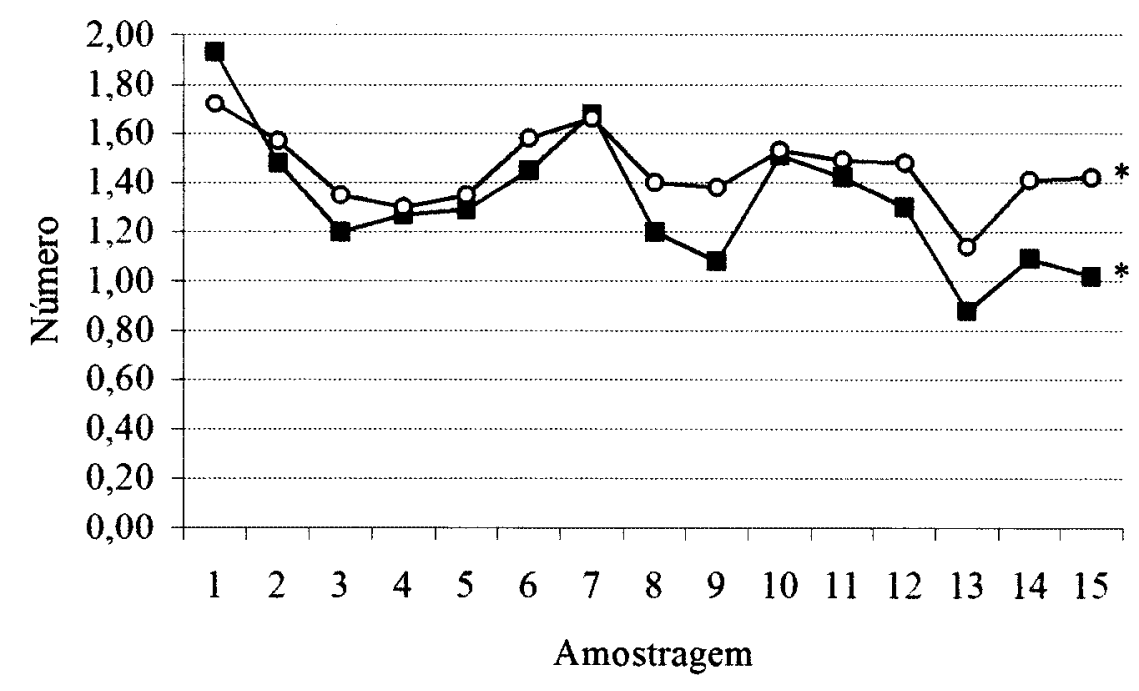

Figura 1 - Resultados do exame California Mastitis Test (CMT) de 15 amostragens com intervalos de aproximadamente 15 dias entre cada uma, realizadas entre o início (setembro/2002, amostragem 1) e o término (junho/2003, amostragem 15) da implantação do sistema de análise de perigos e pontos críticos de controle (APPCC): ( $\square$ ) Número médio de quartos afetados com mastite; (O) Escore de mastite. * Significante $(\mathrm{P}<0,05)$.

$(\mathrm{P}<0,05)$ no período, reduzindo de 1,72 para 1,42 . Conseqüentemente, o sistema appcc mostrou-se eficiente para diminuir a severidade dos casos de mastite no rebanho estudado.

As variações dos valores de \%vm, \%vmc e \%ncm encontram-se na figura 2 . Apesar da tendência de queda da \%vm, não houve diferença significativa $(\mathrm{P}>0,05)$ entre os valores obtidos nas amostragens, permitindo concluir que a implantação do sistema appcc não apresentou efeito sobre a porcentagem de vacas acometidas com mastite.

Não foram encontradas diferenças estatísticas $(\mathrm{P}>0,05)$ entre os valores de \%vmc ao longo das amostragens (Figura 2). Os dados referentes à \%vmc foram calculados a partir da $6^{\mathrm{a}}$ amostragem, uma vez que levou em consideração os animais cujo leite apresentou positividade ao exame de cmt em pelo menos 1 quarto, durante 2 meses consecutivos anteriores. Este resultado é condizente com a metodologia utilizada no estudo, uma vez que, em nenhum momento da implantação do sistema, os perigos relacionados aos animais com mastite crônica foram controlados. Um fato interessante a ser destacado é o grande número de animais que já apresentavam mastite sub-clínica antes do início da implantação do sistema appcc, evidenciado pelos 


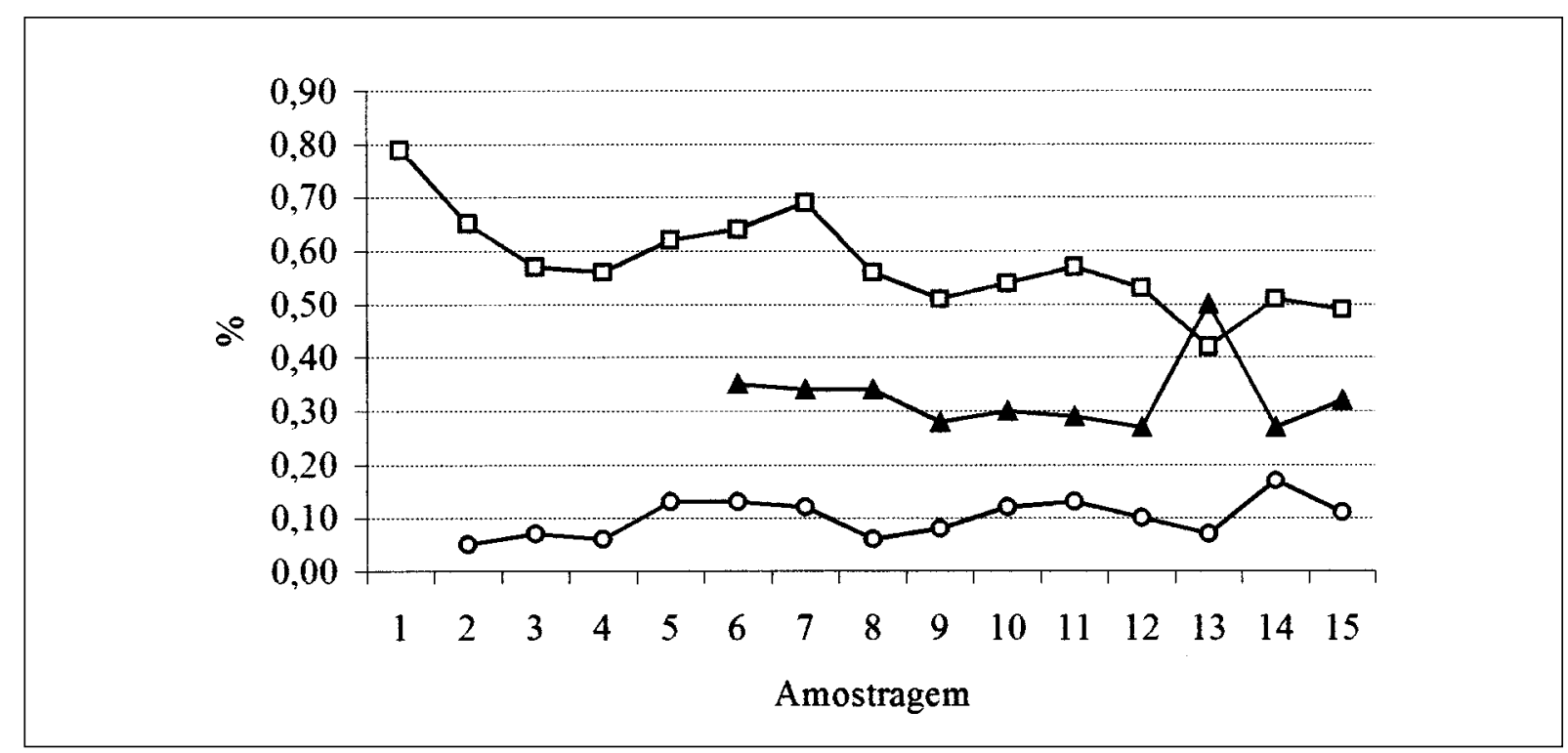

Figura 2 - Variáveis calculadas a partir do exame California Mastitis Test (CMT) de 15 amostragens com intervalos de aproximadamente 15 dias entre cada uma, realizadas entre o início (setembro/2002, amostragem 1) e o término (junho/2003, amostragem 15) da implantação do sistema de análise de perigos e pontos críticos de controle (APPCC): ( $\square$ ) Porcentagem de vacas com mastite; ( $\boldsymbol{\Delta}$ ) Porcentagem de vacas com mastite crônica; (O) Porcentagem de novos casos de mastite.

resultados do exame cmt das amostragens 1 e 2 (Figura 1). Estes animais permaneceram a maior parte do experimento com mastite e, possivelmente, devem ter apresentado a maior porcentagem de cura somente no período seco.

De forma semelhante aos casos anteriores, os valores obtidos para \%ncm (figura 2) não apresentaram variações significativas $(\mathrm{p}>0,05)$ a partir da $2^{a}$ amostragem (pois este dado foi calculado levando-se em consideração os animais com leite positivo no exame de cmt realizado no mês, mas não no mesmo teste realizado no mês anterior), indicando que a aplicação do sistema appcc não teve efeitos sobre a porcentagem de novos casos de mastite. Este fato se deve, provavelmente, ao não controle de todos os perigos identificados ou à exclusão de perigos de difícil controle na rotina diária da propriedade. A manutenção dos perigos e dos altos valores de \%vmc e \%ncm podem ter contribuído para impedir uma redução evidente da ccs e dos demais parâmetros analisados.

\section{CONCLUSÕES}

A aplicação do sistema APPCC mostrouse eficiente para o controle de coliformes fecais no leite, embora não tenha influenciado a contagem de microrganismos mesófilos e psicrotróficos. A implantação do sistema não afetou a CCS no leite de mistura e os percentuais de casos de mastite, porém reduziu o número de quartos afetados e a severidade dos casos de mastite, na avaliação pelo teste de CMT.

Dentre as principais dificuldades encontradas destacaram-se: motivação e envolvimento de funcionários para a nova rotina implementada; dificuldades de tomada de decisão rápida, muitas vezes necessária para o controle de perigos e pontos críticos; falta de dados indicando, de maneira precisa, os limites críticos e as formas de monitoramento do trabalho; necessidade de um tempo maior para a correção de diversos perigos e pontos críticos, indicando que muitas das práticas adotadas apenas resultaram em efeitos observáveis a longo prazo. Estas dificuldades indicam que, na propriedade leiteira, o controle de PCCs depende, fundamentalmente, da atuação da equipe de trabalho, tornando a aplicação dos princípios mais difícil e complexa do que na indústria de alimentos.

\section{AGRADECIMENTOS}

À Fundação de Amparo à Pesquisa do Estado de São Paulo (FAPESP) - processo n. 01/04391-7.

\section{REFERÊNCIAS}

AMERICAN PUBLIC HEALTH ASSOCIATION. Standard methods for the examination of dairy products. 16.ed. Washington: APHA, 1992.

Ciência Rural, v.35, n.6, nov-dez, 2005. 
ARMITAGE, P.; BERRY, G. Statistical methods in medical research. Boston: Blackwell, 1987. 559p.

BOGDAN, R.C.; BIKLEN, S.K. Investigação qualitativa em educação: uma introdução à teoria e aos métodos. Porto, Portugal: Porto, 1994. 336p.

BRASIL. Ministério da Agricultura. Regulamento de inspeção industrial e sanitária de produtos de origem animal. Brasília: MA, 1976. 166p.

BRASIL. Ministério da Agricultura, Pecuária e Abastecimento. Instrução Normativa n. 51, de 18 de setembro de 2002. Diário Oficial da República Federativa do Brasil, v.1, p.??, 2002

Cezari, D.L.; NASCIMENTO, E.R. Análise de perigos e pontos críticos de controle - APPCC. Rio de Janeiro: SBCTA, 1995. 29p.

CULLOR, J.S. HACCP (Hazard Analysis Critical Control Points): Is it coming to the dairy ? J Dairy Sci, v.80, p.34493452, 1997

FONSECA, L.F.L.; SANTOS, M.V. Qualidade do leite e controle de mastite. São Paulo: Lemos Editorial, 2000. $175 p$.

MARTIN, C.; CICHOSKI, A.J. Estudo da aplicação do método APPCC (análise de perigos e pontos críticos de controle) numa queijaria - I) a água utilizada. Higiene Alimentar, v.14, p.77-82, 2000.

MILLER, R.H. et al. The relationship of milk somatic cell count to milk yields for holstein heifers after first calving. J Dairy Sci, v.76, p.728-733, 1993.

PEREIRA, J.C.R. Análise de dados qualitativos: estratégias metodológicas para as Ciências da Saúde,
Humanas e Sociais. 3.ed. São Paulo: EDUSP. 2001. 120p. Philpot, W.N.; NICKERSON, S.C. Vencendo a luta contra a mastite. São Paulo: Milkbizz, 2002. 192p.

Ribas, N.P. Importância da contagem de células somáticas para a saúde da glândula mamária e qualidade do leite. In: SIMPOSIO INTERNACIONAL SOBRE PRODUCAO INTENSIVA DE LEITE, 4., 1999, Caxambu, MG. Anais... São Paulo: Instituto Fernando Costa, 1999. p. 36-43

RONCA, A.C.C.; ESCOBAR, V.F. Técnicas pedagógicas. 5.ed. Rio de Janeiro: Vozes, 1988. 113p.

SERVIÇO NACIONAL DA INDÚSTRIA. Guia para elaboração do plano APPCC - laticínios e sorvetes. Brasília: Senai/DN, 2000. 162p.

SILVA, F.T.; GOMES, C.A.O. Segurança alimentar de leite e derivados: aplicação de BPF e APPCC. In: PORTUGAL, J.A.B. et al. O agronegócio do leite e os alimentos lácteos funcionais. Juiz de Fora: EPAMIG, 2001. p.109150 .

SISCHO, W.M. Symposium: drug residue avoidance: the issue of testing - quality milk and tests for antibiotic residues. J Dairy Sci, v.79, p.1065-1073, 1996.

SOARES, J. et al. Análise de pontos críticos no abate de frangos, através da utilização de indicadores microbiológicos. Higiene Alimentar, v.16, p.53-61, 2002.

SPREER, E. Lactologia industrial. 2.ed. Zaragoza: Acribia, 1991. 617p.

VEISSEYRE, R. Lactologia tecnica. Zaragoza: Acribia, 1972. 643p. 